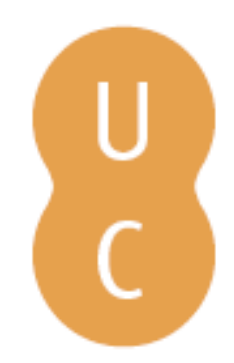

\title{
pommalina
}

\section{What moves at the margin: as vozes insurretas de Toni Morrison, bell hooks e Ntozake Shange}
Autor(es):
Caldeira, Isabel
Publicado por: Imprensa da Universidade de Coimbra
URL
persistente:
http://hdl.handle.net/10316.2/42312
DOI:
https://doi.org./10.14195/978-989-26-1308-6_4
Accessed : $\quad$ 11-Sep-2017 17:00:30

A navegação consulta e descarregamento dos títulos inseridos nas Bibliotecas Digitais UC Digitalis, UC Pombalina e UC Impactum, pressupõem a aceitação plena e sem reservas dos Termos e Condições de Uso destas Bibliotecas Digitais, disponíveis em https://digitalis.uc.pt/pt-pt/termos.

Conforme exposto nos referidos Termos e Condições de Uso, o descarregamento de títulos de acesso restrito requer uma licença válida de autorização devendo o utilizador aceder ao(s) documento(s) a partir de um endereço de IP da instituição detentora da supramencionada licença.

Ao utilizador é apenas permitido o descarregamento para uso pessoal, pelo que o emprego do(s) título(s) descarregado(s) para outro fim, designadamente comercial, carece de autorização do respetivo autor ou editor da obra.

Na medida em que todas as obras da UC Digitalis se encontram protegidas pelo Código do Direito de Autor e Direitos Conexos e demais legislação aplicável, toda a cópia, parcial ou total, deste documento, nos casos em que é legalmente admitida, deverá conter ou fazer-se acompanhar por este aviso.

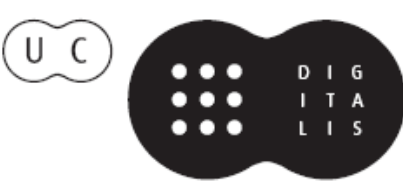





\section{"WHAT MOVES AT THE MARGIN" : AS VOZES INSURRETAS DE TONIMORRISON, BELL HOOKS E NTOZAKE SHANGE ${ }^{1}$}

Isabel Caldeira

Resumo: Neste texto procuro demonstrar como escritoras afro-americanas como Toni Morrison, Ntozake Change, ou bell hooks, depois da década de 70 do século $\mathrm{XX}$, revêem modelos de discurso e representação, ora apropriando-se deles e reinventando-os, ora subvertendo-os numa linguagem que assim se torna sua e negra. Debatendo-se na tensão entre a libertação pela linguagem e o aprisionamento que ela também constitui, propõem-se escolher as margens (hooks) para desconstruir um discurso hegemónico, naturalizado e transparente, que se arroga o direito de ser totalizador, universal e é, afinal, "branco" e patriarcal. Por isso é insurreto o discurso que se move nas margens, reclamando na sua insurreição o mais genuíno sentido de cidadania plena.

${ }^{1}$ A minha paixão pela literatura e cultura afro-americana, que não se esgotou em todos estes anos de estudo, devo-a à minha Mentora, Maria Irene Ramalho Santos, com quem comecei por conhecer Richard Wright, Ralph Ellison e Malcolm X nos idos anos de 1970. O seu saber imenso, distribuído pelas suas diversas paixões, tem sido uma contínua inspiração. A sua amizade uma jóia preciosa! 
Palavras-chave: escritoras afro-americanas; Toni Morrison; Ntozake Shange; bell hooks; racismo.

\begin{abstract}
In this text I examine how African-American female writers, such as Toni Morrison, Ntozake Shange, or bell hooks revise dominant models of discourse and representation, either by appropriation and reinvention, or subversion, creating both a literature of their own and a black literature. In their deconstruction of a hegemonic discourse, which claims to be universal, totalizing, and is, after all, "white" and patriarchal, I sense a tension between language as both liberating and imprisoning. These women writers therefore choose the margin as "a space of radical openness" (hooks) to offer us an insurgent discourse which fulfils their call for full citizenship.
\end{abstract}

Keywords: African-American female writers; Toni Morrison; Ntozake Shange; bell hooks; racism.

We've only just begun . . . to fashion a woman's vocabulary to deal with the "silences" of our lives.

Toni Cade Bambara (in Tate 1983)

It's not that we haven't always been here, since there was a here. It is that the letters of our names have been scrambled when they were not totally erased, and our fingerprints upon the handles of history have been called the random brushings of birds. . . But Black women have survived. And our words have survived.

Audre Lorde (1989) 
And all the while the richness of our embodied difference pulses between us and through us, beckoning our attention, too fluid and vivid to be quantified at all, least of all as equal.

Irene Ramalho Santos (2013)

But Some Of Us Are Brave: All the Women Are White, All the Blacks Are Men: Black Women's Studies é o título de uma antologia publicada nos Estados Unidos em 1982, que reúne textos fundadores do Feminismo Negro (Black Feminism). O título denuncia a dupla exclusão sentida pelas mulheres negras em relação à visão hegemónica do Movimento Feminista, liderado por mulheres brancas de classe média, cuja acção lhes era pretensamente dirigida também, e ao nacionalismo negro, liderado por homens, invisibilizando as mulheres e acorrentando-as a ideais masculinos e patriarcais. Nos textos reunidos na antologia reflecte-se uma consciencialização amadurecida pelas lutas pelos direitos cívicos das décadas de 60 e 70 nos Estados Unidos, embora as mulheres negras tivessem sido relegadas para a retaguarda.

É também na década de 1970 que Adrienne Rich nos oferece uma reflexão sobre re-visão, inspirada por esse tempo de mudança e de esperança, que ela não deixava de sentir como, a um tempo, confuso e doloroso - "It's exhilarating to be alive in a time of awakening consciousness; it can also be confusing, disorienting, and painful” (Rich 1972: 18). Bem previa Rich, nesta sua ambivalência, que os frutos da movimentação social que observava à sua volta trariam debaixo da doçura o rasto acre da luta sempre incompleta e demasiadas vezes sujeita a recuos. Quando Rich se interroga sobre os fatores da opressão das mulheres, se estarão no sistema económico de classe ou na estrutura sexual de classe, não entra no 
seu raciocínio a raça, o outro fator ideológico subjacente à ordem ocidental desde o colonialismo, a "colonialidade do poder" ${ }^{2}$, que na divisão social do trabalho do capitalismo se orientou pela divisão racial. ${ }^{3}$ Por isso, a muitas mentes esclarecidas e clarividentes como a de Adrienne Rich, outras tiveram que se juntar, para com a sua experiência vivida numa "outra metade" da América ajudarem a despertar "os sonâmbulos" para novas realidades políticas. Mas, para isso, é imperioso re-ver "from a new critical direction", como Rich nos incentiva a fazer, uma re-visão que ela apresenta como "an act of survival", levado a cabo pelas mulheres que pretendam deter o processo da sua própria auto-destruição ou invisibilização. Um dos aspetos deste processo faz-se, também para Rich, através da linguagem, para entender "how our language has trapped as well as liberated us" (Rich 1972: 18, ênfase minha).

Neste tipo de preocupação, Rich alinha perfeitamente com escritores e escritoras de grupos minoritários, dupla ou triplamente invisibilizados. ${ }^{4}$ Também na década de 1970, um escritor afro-americano, Ralph Ellison, refletia sobre a língua inglesa, que era também dele, mas ao mesmo tempo o excluia, pois nela se inscrevia, inexoravelmente, a discriminação racial:

Perhaps the most insidious and least understood form of segregation is that of the word. And by this I mean the word in all its complex formulations. . . For if the word has the potency to

2 Refiro-me ao conceito de "colonialidade do poder" proposto por Anibal Quijano (2000).

3 Para o entendimento da forma como o capitalismo gerou a divisão racial, veja-se o artigo de Quijano e Wallerstein (1992).

${ }^{4}$ Um exemplo significativo desta solidariedade está na combinação entre Rich, Audre Lorde e Alice Walker, todas nomeadas para o National Book Award para a poesia em 1974, de que, fosse qual fosse a que ganhasse, partilhariam o prémio e o usariam, da melhor forma, em prol das mulheres. Foi Rich a ganhá-lo e leu na cerimónia de entrega uma declaração nesse sentido escrita pelas três. 
revive and make us free, it has also the power to blind, imprison and destroy. (Ellison 24)

Mais tarde, bell hooks, outra intelectual afro-americana, na sua obra de 1990, Yearning, mais especificamente no capítulo que intitula "Choosing the Margin as a Space of Radical Openness", ecoa a retórica dos sermões afro-americanos na repetição coralista da frase "Language is also a place of struggle", para se questionar sobre as possibilidades de expressão numa língua que traz a marca da opressão, mas que ela pretende re-animar com a energia da luta e da resistência:

Dare I speak to you in a language that will move beyond the boundaries of domination - a language that will not bind you, fence you in, or hold you? Language is also a place of struggle. The oppressed struggle in language to recover ourselves, to reconcile, to reunite, to renew. Our words are not without meaning, they are an action, a resistance. (146)

Esta reflexão sobre a tentativa de apropriação de uma língua contaminada, porque foi sempre o veículo da dominação, está presente em muitas vozes que pensam sobre as marcas de um passado de colonialismo e racismo nas vidas, nos corpos e, perigosamente, nas mentes colonizadas. Esta preocupação parece-me predominante no texto esfíngico que Toni Morrison escreveu para o seu discurso de agradecimento do Prémio Nobel, em 1993. Morrison recorre à metáfora para falar da linguagem como um organismo vivo e da sua utilização como um acto de grande responsabilidade - "an act with consequences" (1994: 13). É esse ensinamento que Morrison transmite através da parábola que é, afinal, esse texto, em que se confrontam uma figura da geração com memória do passado de escravatura e dois jovens. A mulher, uma filha de escravos, muito 
idosa, cega e cheia de sabedoria, aprendeu com o sofrimento a preservar com muito cuidado as formas de vida da língua, porque a língua estiolada pela dominação e pelo preconceito é, para os negros, uma língua morta: "characterized as censored and censoring, the language of dominance, which preserves privilege, sanctions ignorance and is $[\mathrm{u}]$ nreceptive to interrogation, it cannot form or tolerate new ideas, shape other thoughts, tell another story, fill baffling silences" (14). Esta é a língua que foi inventada "for the estrangement of minorities, hiding its racist plunder in its literary cheek. . . Sexist language, racist language, theistic language, which limits knowledge, and tucks its fascist boots under crinolines of respectability and patriotism" (16). Para re-ver e re-animar a linguagem, propõe-se a escritora uma tarefa, abrir espaço para novas sonoridades:

A sound made up of all the elements that distinguished black life (its peculiar brand of irony, oppression, versality, madness, joy, strength, shame, honor, triumph, grace and stillness) as well as those qualities that identified it with all mankind (compassion, anger, foolishness, courage, self-deception and vision). ("Rediscovering Black History" 43)

A lista de emoções e atitudes não basta para caracterizar essa especificidade da língua falada pelos negros, por isso vem a necessidade de nomear os sujeitos dessa fala, os anónimos, homens e mulheres, que nas histórias convencionais são falados por quem tem o poder. Mas nem assim é possível explicar. Ainda no discurso do Nobel, vem a interrogação: "What makes a work 'black'?" (1994: 136). Como resposta, uma nova lista, ela própria expressão da dificuldade em definir, mas, desta vez, incorporando na linguagem a diferença cultural e racial, que se sintetizam numa estratégia de insurreição: "The most valuable point of entry into the question of 
cultural (or racial) distinction, the one most fraught, is its language - unpoliced, seditious, confrontational, manipulative, inventive, disruptive, masked, and unmasking language" (ibidem).

Desde finais da década de 70 do século XX, mais propriamente desde a publicação de Orientalism por Edward Said (1978), que a desconstrução de uma visão hegemónica do Outro, erigida pelo império colonial europeu, tentou deslocar o ponto de vista de análise e teorizar aquilo que se denominou perspectiva pós-colonial. ${ }^{5} \mathrm{Em}$ 1989 surgiu a obra de referência para esta linha teórica: The Empire Writes Back: Theory and Practice in Post-Colonial Literatures de Bill Ashcroft, Gareth Griffiths e Helen Tiffine. Se a menciono, é porque nela se enunciam conceitos fundamentais para esta minha análise: império, hegemonia, estratégias de reposição ("re-placement") - revogação e apropriação - dos modelos de discurso e representação, em busca de um reforço de identidade e emancipação para sujeitos que foram vítimas de processos de colonização, destituição e silenciamento.

Neste trabalho interessa-me propor uma nova reposição - em vez do Outro, a Outra, em vez de "the empire writes back", "the ghetto writes $\mathrm{B}[1] \mathrm{ack}$ ", a formulação e o sentido da escritora afro-americana Sherley Anne Williams, no seu ensaio de 1993, "The Lion's History: The Ghetto Writes B[1]ack". Quando Williams escreve este artigo, o seu intuito é chamar a atenção para o momento em que os negros - homens e mulheres - saem do silêncio a que tinham sido votados e, ao fazê-lo, elevam vozes que reclamam a sua própria especificidade, tanto porque se re-posicionam numa história que se propõem re-escrever - porque estão cansados e cansadas de sofrer a obliteração e a deformação da história hegemónica - como porque querem

\footnotetext{
5 Uso o termo pós-colonial não no seu sentido cronológico, mas sim cultural, na peugada de Ramón Saldivar, como um conceito dentro da lógica de culturas marcadas pelo imperialismo e pelo racismo (cf. "Historical Fantasy, Speculative Realism, and Postrace Aesthetics in Contemporary American Fiction." American Literary History 23.3 [Fall 2011]: 575).
} 
revogar modelos de discurso e representação, ora apropriando-se deles, ora reinventando-os e subvertendo-os numa linguagem que assim se torna sua e negra, num movimento que é de rei-vindicáre ("write back"), ou seja, reclamar aquilo que é seu.

É esta preocupação que encontro, por exemplo, na literatura produzida por mulheres afro-americanas, vozes que se elevam contra o racismo, o sexismo, a hegemonia cultural do império e do patriarcado que removeram as suas vidas e memórias para espaços de subalternização, que as desvalorizam e apoucam. Delas recebemos também os sinais da resistência. "Language is also a place of struggle"! lê-se à guiza de refrão, ou coro, no texto de bell hooks (1990), que convoca os sons e imagens "that mainstream consumers find difficult to understand" (147). Para a autora, é preciso fazer o esforço de incluir as "múltiplas vozes" negras no discurso, mesmo o académico, para abrir nele o espaço para a oralidade, para o vernáculo - "talking the talk". hooks surge-me, assim, na peugada do crítico Houston Baker, Jr., que, já em 1987, propunha uma nova forma de ler toda uma tradição discursiva afro-americana a partir do vernáculo e dos blues (1987); ou do crítico Henry Louis Gates, Jr. que, um ano mais tarde, buscava a especificidade da cultura afro-americana na matriz Yoruba do "signifying monkey", perpetuada nos rituais discursivos do "signifying" (1988). Afinal, o que aqui testemunhamos é o ato político de intervenção como dissenção numa língua que os disse escravos, levando-os desde sempre a desconfiar dela. Por isso, temos Houston Baker numa obra posterior (1989) a caracterizar a voz afro-americana como aquela a quem não basta dominar os códigos do discurso dominante - "mastery of form" -, mas sim avançar para uma subversão desses mesmos códigos - "deformation of mastery". 6 Afinal, trata-se de encontrar a linguagem rebelde,

\footnotetext{
${ }^{6}$ Houston Baker encontra exemplos vários dessa subversão de códigos e desmontagem irónica dos discursos dominantes que caracteriza o discurso afro-americano.
} 
subversiva, inventiva e insubordinada, capaz de desmascarar, e ao mesmo tempo hábil no utilizar das máscaras, de que fala Morrison, que escolheu para si própria o epíteto de "saboteur". ${ }^{7}$

Mas interessa-me refletir ainda sobre o sentido que bell hooks, na obra acima referida, coloca na expressão "intimate intervention", que ela explana como "[p]rivate speech in public discourse", o lado íntimo da linguagem "normally save[d] for family and loved ones" (147), abrindo um espaço seu (e para a comunidade negra) numa língua que lho negou. Em todo o seu texto se pressente a tensão entre o esforço para o conseguir e a frustração nele envolvida, visível no anacoluto: “. . . making another text, a space that enables me to recover all that I am in language, I find so many gaps, absences in this written text" (147). Ao lado político da intervenção como dissenção alia-se a dimensão de intimidade e sentimento que convoca uma vivência comunitária para imaginativamente a fortalecer, visível na prefixação que compõe uma rima inicial "to recover ourselves, to reconcile, to reunite, to renew" (146) - e ao mesmo tempo arredar o Outro, o "mainstream consumer" (o branco?) da comunicação. Conquistado um espaço seu, está consciente de que não pode ser um espaço seguro ("[i]t is not a 'safe' place"), mas que lhe possibilita, ainda assim, a reunião de uma comunidade de resistência ("a community of resistance") (149). bell hooks tem o cuidado de explicitar o sentido positivo de margem que, quando imposta, habitualmente é conotada com inferiorização e discriminação, mas quando é escolha pode ser um local de resistência: "I am located in the margin. I make a definite distinction between that marginality which is imposed by oppressive structures and that marginality one

\footnotetext{
Um primeiro exercício do crítico está na análise da figura de Trueblood em Invisible Man de Ralph Ellison. Uma maior elaboração dessa primeira tese está patente na sua obra Modernism and the Harlem Renaissance (1989).

7 Esse epíteto é mencionado por Adam Langer, na entrevista que lhe faz, em 2003 (Langer 212).
} 
chooses as site of resistance - as location of radical openness and possibility" (hooks 153).

Está, assim, encontrada uma fonte de energia para levar a cabo a abertura de novos mundos, novas alternativas (149-150). No texto de Rich que atrás referi, "When We Dead Awaken", diz-nos a autora que, se a imaginação "is to transcend and transform experience it has to question, to challenge, to conceive of alternatives" (23).

É na margem escolhida como espaço de "radical oppenness" (hooks 153), que vejo o sentido de "interstices", tal como Homi Bhabha os apresenta em The Location of Culture, como os espaços em que "the intersubjective and collective experiences of nationness, community interest, or cultural value are negotiated" por grupos que partilham histórias de despojamento e discriminação. (2). Mas, para aqueles e aquelas que escolhem a margem, em vez de viverem de facto na margem, a negociação é bem mais consciente.

À ideia de resistência (hooks) e de negociação (Bhabha), Toni Morrison acrescenta a ideia de soberania (1998). Para ela, o exercício de linguagem que é a escrita de ficção pode constituir-se como espaço de soberania e autoridade, talvez o único possível para quem conhece a dupla opressão por ser mulher e negra. E à noção de hooks de "intimate intervention", Morrison contrapõe uma "deliberate intervention". A conquista de poder através da linguagem permite combater "the potency of racist constructs". Só assim "the racist house" se poderá converter em "home" (idem: 4). A constituição de um espaço comunitário exclusivo através da linguagem, tal como é proposto por hooks, encontra eco em Morrison quando esta privilegia um público leitor negro: "I'm interested in black readers and me" (idem: 109). Novamente se percebe um sentido comunitário numa experiência partilhada, que não tem de ser explicada para fora da comunidade:

There are certain things I don't want to expose, not because Whites shouldn't know, but they are not who I'm addressing the 
book to. The Black people who never pick up a book - the Black people in my books who don't read books - are the people who authenticate that book for me. (idem: 15)

A referência à autenticação não é gratuita. Traz consigo a associação à necessidade vivida pelos ex-escravos ou escravos foragidos, autores de narrativas autobiográficas que serviam a causa abolicionista. Esses textos tinham sempre que ser "autenticados" por abolicionistas ou outros brancos respeitáveis da comunidade, chamados a atestar quer a verdade das experiências narradas, quer a autoria, já que esta não condizia com as expectativas de um público que crescera na convicção da inferioridade intelectual dos negros. ${ }^{8}$

A outro nível, mas na mesma linha de rebeldia e subversão na linguagem, encontro na ficção de Toni Morrison a tematização da noção de "wildness", associada à forma como os negros são percecionados na sociedade americana. Em Jazz, o seu romance de 1992,? “wild” começa por ser a própria música de jazz, que é referida como "the dirty, get-on-down music the women sang and the men played and both danced to, close and shameless or apart and wild" ( $J$ 58). É ela que invade a cidade, junto com os migrantes negros vindos do Sul para Harlem, nas primeiras décadas do século XX. O jazz é representado no texto como a irrupção de uma "complicated anger",

\footnotetext{
8 Neste contexto, é fácil entender como o acesso à alfabetização e à escrita se tornou um instrumento fundamental para a emancipação. Houve quem chamasse à palavra um "certificado de humanidade" (Paulin Hountondji, citada por Henry Louis Gates, Jr., em "Writing 'Race' and the Difference It Makes." Critical Inquiry 12.1 [Autumn 1985]: 12). Uma obra pioneira para a primeira fase de definição de uma tradição literária afro-americana pós-década de 60 é a de Robert Stepto, From Behind the Veil: A Study of Afro-American Narrative (Champaign, IL: University of Illinois Press, 1979). Nela, o crítico traça a linha matricial do discurso afro-americano a partir da conquista da palavra, o que se traduziu num processo que começou pela necessidade de autenticação, passou pela auto-autenticação e caminhou em direção a uma total autonomia.

9 Doravante, as referências a Jazz serão parentéticas com a inicial $J$ e o n. ${ }^{\circ}$ de página.
} 
acumulada num passado de opressão e discriminação, na memória mais recente da exploração económica e dos linchamentos no Sul, a que se acrescentam as novas dificuldades na competição capitalista no meio urbano, na segregação do gueto, ou na revolta dos veteranos de guerra, abandonados ao seu não-destino - um cocktail explosivo rebentando a par e passo em tumultos raciais em várias cidades. Tal como comenta Doreatha Mbalia,

Wild, in Jazz, signifies defiance, rebelliousness, aggressiveness, and silence - all caused by class exploitation and race and/ or gender oppression. Because conditions throughout the U.S., indeed the world, in the 1920s are so oppressive for African people, there are traces of Wild in everything and everyone. (JMbalia 106)

Mbalia, quando escreve com maiúsculas a palavra, está já a converter a personagem com esse nome numa espécie de alegoria. Wild é referida pela crítica como o ressurgimento da personagem Beloved do romance homónimo de $1987 .{ }^{10} \mathrm{Em}$ ambos os casos, trata-se de personagens intrigantes, que não se deixam conter nos padrões convencionais de uma tradição racional ocidental e os põem em causa. Wild é a mulher estranha e misteriosa que habita os bosques e os canaviais, vive numa gruta e ninguém consegue bem entender. A sua nudez, a pele intensamente negra, os olhos de gazela, e o facto de estar grávida e dar à luz uma criança que não sabe tratar como filho aumentam a sua associação a uma natureza selvática. Vai deixando vestígios pelo seu caminho, "traces", refere o texto, e é por isso que o filho adota o nome de Joe Trace. Joe sofre o abandono

10 Numa entrevista, a própria autora reforça essa associação: "Wild is a kind of Beloved. . . . The woman they call Wild. . . could be Sethe's daughter, Beloved. . . who runs away, ending up in Virginia, which is right next to Ohio" (Carabi 96). 
e procura a mãe, seguindo esses vestígios, sem nunca a encontrar. Não podemos deixar de nos lembrar do sentido de traço ("trait") em Derrida e essa busca humana de sentido condenada à frustração e/ou a possibilidade de retorno ("retrait"). ${ }^{11} \mathrm{Na}$ busca incessante e frustrada de Joe alegoriza-se a busca incessante e frustrada de um passado perdido para os descendentes dos Africanos feitos escravos e nesse processo privados para sempre de uma origem com possibilidade de regresso. Mas Wild é também vestígio de um passado que teima em retornar.

Em Beloved (1987), o primeiro romance em que a escritora intenta representar o passado de escravatura, Morrison utiliza significativamente o termo "rememory", pois a memória direta há muito se perdeu. ${ }^{12} \mathrm{Na}$ boca de Sethe, que tenta explicar à filha Denver a forma como não se consegue fugir ao passado, surge esse termo e a noção de que não se trata apenas de memórias individuais, mas sim do acesso a um passado partilhado: "Someday you be walking down the road and you hear something going on. So clear. And you think it's you thinking it up. A thought picture. But no. It's when you bump into a rememory that belongs to somebody else" ( $B$ 36). E é por isso que o passado de escravatura nunca se apagou. Nem da memória dos negros, nem da memória dos brancos. Não está a identidade de uns implicada na dos outros? Beloved é o fantasma encarnado da filha morta, que não só traz consigo o reviver do trauma para Sethe, ou a hipótese de libertação, mas também os fragmentos

\footnotetext{
${ }^{11}$ Para um estudo que também lê "trace" à luz de "trait" de Derrida, cf. Sandra Regina Goulart Almeida. "O legado da rememoração: traços e vestígios memoriais nas Américas." Alea 15.1 Rio de Janeiro (Jan./Junho 2013). Web. 13.03.2015.

12 Poderemos relacionar a noção de "rememory" com o conceito de "prosthetic memory", tratado por Alison Landsberg em Prosthetic Memory: The Transformation of American Remembrance in the Age of Mass Culture (New York, NY: Columbia UP., 2004) e o de "postmemory", estudado por Marianne Hirsh em The Generation of Postmemory: Writing and Visual Culture After the Holocaust (New York, NY: Columbia UP, 2012). Doravante, as referências a Beloved serão parentéticas com a inicial $B$ e o n. ${ }^{\circ}$ de página).
} 
de uma memória da escravatura que remonta a África e ao trauma originário do abandono - da terra, dos entes queridos, das origens. É neste mesmo romance que Morrison utiliza, para esses "traços" ("traits") do passado, a expressão "unspeakable things unspoken", a memória da violência que tenta irromper na palavra, mas se retrai ("retrait"), pois certas realidades são inomináveis. ${ }^{13}$

A associação de Wild à natureza, à selva (que nos faz retornar a Beloved e à forma irónica como Morrison utiliza esta como metáfora - "White people believed that whatever the manners, under every dark skin was a jungle." (B 198-99) $)^{14}$ - sugere a perceção negativa que se impôs à população de origem africana nos E.U.A., colada à perceção da própria África como um mundo não civilizado. No dizer de Morrison, para a sociedade branca, as gentes de origem africana continuaram a ser a um tempo "unsettled and unsettling" (1992b: 6). A reflexão sobre essa presença africana na sociedade americana desde os seus primórdios - "which shaped the body politic, the Constitution, and the entire history of the culture (idem: 5) deu origem a uma série de conferências na Universidade de Harvard, depois coligidas e publicadas em Playing in the Dark (1992). Aí, Morrison propõe o conceito de "Africanismo" num sentido novo, a figuração simbólica da presença (feita ausência) dos Afro-americanos na literatura americana, "constructs of blackness" com que o discurso nacional codificou uma presença desde o início incómoda. Tratando-se de uma invenção, um tropo - observa Morrison: "the denotative and conotative blackness that African peoples have come to signify, as well as the entire range of views, assumptions, readings,

13 Derrida joga com as noções de traço (trait) e retrair, retroceder (retrait): enquanto a primeira noção sugere a memória de uma identidade, quando a linguagem intenta dar-lhe forma, a segunda sugere a incapacidade da linguagem, dada a sua contingência e a limitação da conceptualização; vem ao de cima o aspecto de palimpsesto do texto, que se dá apagando-se, escondendo-se, retraindo-se.

${ }^{14}$ V. meu artigo "Morrison and Pepetela" (2008). 
and misreadings that accompany Eurocentric learning about these people" (idem 6-7) -, tem servido no discurso não só para implicar, veladamente, a presença dos negros, mas também para a controlar e policiar, ao nível da classe, da sexualidade, e do exercício do poder. A presença dos Africanos converte-se, assim, em ausência, e é por isso que a escritora intenta desvelá-la e comprovar que eles estiveram lá sempre "playing in the dark". Ganha, pois, um profundo significado essa tensão que observo entre a imperiosa necessidade de desvelar, pela incisão do traço ("trait"), o que foi obliterado ("unspoken") e a incapacidade de dizer porque há realidades que são indizíveis ("unspeakable"), e a linguagem, que é humana, é débil, contingente e limitada ("retrait").

À fixidez do esterótipo (Bhabha), contrapõe Morrison, ironica e subversivamente, novas figurações de "wildness", incorporadas em várias mulheres que percorrem os seus textos, todas elas fortes e perturbadoras. ${ }^{15}$ A Beloved e a Wild acrescentam-se, assim, outras figuras de mulheres rebeldes na ficção morrisoniana, que afrontam valores convencionais, como é o exemplo paradigmático de Sula, no romance homónimo de 1973. Na entrevista de Adam Langer, de 2003 , a própria Morrison refere a ideia da "wanton woman", "anarchic figure", "pariah", figura presente em quase todos os seus livros (230). Pensamos em Pilate de Song of Solomon, Thérese de Tar Baby, Junior de Love, Florens de A Mercy, ou mesmo Bride de God Help the Child. Na sua "wildness", parecem deixar no seu caminho reminiscências, ou "traços", de uma origem africana; ou

\footnotetext{
15 Para estudos que têm como centro figuras de mulheres insurgentes na ficção, veja-se, por exemplo: Joanne M. Braxton \& Andree Nicola McLaughlin. Wild Women in the Whirlwind: Afra-American Culture and the Contemporary Literary Renaissance (Chapel Hill, NC: Rutgers University Press, 1989); Molly Hite. The Other Side of the Story: Structures and Strategies of Contemporary Feminist Narratives (Ithaca, NY: Cornell University Press, 1989); Elliott Butler-Evans. Race, Gender, and Desire: Narrative Strategies in the Fiction of Toni Cade Bambara, Toni Morrison, and Alice Walker (Philadelphia, PA: Temple University Press, 1991).
} 
tornam-se "wild", numa loucura que irrompe da tensão acumulada, tal como em Sethe, quando corre a atacar Mr. Bodwin, desvairada pela memória daquele dia traumático em que viu a aproximar-se os brancos que a reclamavam, a ela e aos filhos ("her best thing"), de volta à escravatura.

$\mathrm{Na}$ minha leitura, estas associações perifrásticas atuam na obra de Morrison como estratégias desconstrutivas de um discurso racista. Maria Irene Ramalho, a propósito da sua teoria da interrupção, considera como o "político-que-interrompe" ". . . a estrutura naturalizada da sociedade ocidental que dá forma às vidas das pessoas e as condiciona, e, ao mesmo tempo, o modo como as pessoas são levadas a perceber e a experienciar a sociedade, e não a capacidade de intervir na sociedade e de a transformar e melhorar" (2000: 2). O discurso naturalizado é "transparente", como nos diz Gayatri Chakravorty Spivak a partir de Derrida, e arroga-se o direito de ser totalizador, universal (1988). E "branco". Na escrita de sujeitos que sempre se viram distorcidos nessa "estrutura naturalizada" e "transparentes" numa narrativa totalizadora que assim os fez ausentes da História, percebe-se a necessidade de resistir à tendência unificadora dos códigos. Daí a urgência de "intervir na sociedade e de a transformar e melhorar" (Ramalho Santos 2000: 2), impondo a sua presença e revertendo uma secular violência epistémica (Spivak). Por isso é insurreto o discurso que se move na margem, reclamando na sua insurreição o mais genuíno sentido de cidadania plena. ${ }^{16}$

Em "The Transformation of Silence into Language and Action", uma palestra apresentada num congresso da Modern Language Association de 1997, Audre Lorde diz:

Each of us is here now because in one way or another we share a commitment to language and to the power of language,

16 V. meu artigo "Toni Morrison and Edwidge Danticat", 2017. 
and to the reclaiming of that language which has been made to work against us. In the transformation of silence into language and action, it is vitally necessary for each and one of us to establish or examine her function in that transformation and to recognize her role as vital within that transformation. (43)

Ntozake Shange já parecia estar a responder a este apelo de Lorde quando, em 1975, levou a um palco nova-iorquino o seu poema dramático (ou "choreopoem", o neologismo com que se auto-apresenta) for colored girls who have considered suicide/when the rainbow is enuf. ${ }^{17}$ Shange reúne sete mulheres no palco, todas elas imóveis "in postures of distress". É no momento da enunciação que cada uma delas, sucessivamente, ganha vida ("come[s] to life"). A voz de cada uma eleva-se, em comunicação com a seguinte, numa cadeia que sugere um laço comunitário de encorajamento mútuo: "sing a black girl's song / bring her out / to know herself" ( $f c g$ 2). A canção (o blues?) traz consigo ritmos de "carin/struggle/hard times" ( $f c g 3$ ), sintetizando vidas sofridas, condenadas ao silenciamento: "she's been dead so long / closed in silence so long / she doesn't know the sound / of her own voice / her infinite beauty" ( $f c g$ 3). Mas não é só a sociedade racista ou a exploração que são vituperadas; um dos principais alvos são os homens negros, representados como predadores e violadores. No texto de Shange é muito mais nítido do que no texto de Morrison um cariz feminista. Cada uma das falas das sete mulheres traz uma história reveladora da interseccionalidade das opressões, sexual, racial e de classe. ${ }^{18}$ Para além disso, há

${ }^{17}$ Doravante, as referências à obra de Shange serão parentéticas com as iniciais $f c g$ e o n. ${ }^{\circ}$ de página.

${ }^{18}$ Para o entendimento do conceito de intersectionalidade, veja-se The Combahee River Collective, "A Black Feminist Statement" (1978).Web; ou Kimberlé Crenshaw, "Mapping the Margins: Intersectionality, Identity Politics, and Violence Against Women of Color"; e Trina Grillo, "Anti-Essentialism and Intersectionality: Tools to 
uma forte dinâmica de solidariedade entre as mulheres, de mútuo incentivo, de "sisterhood". A música anima os corpos e as mulheres dançam em ritmos cada vez mais vigorosos, num movimento de corpos sexualizados e erotizados que não escondem nem reprimem o desejo, libertando gradualmente a dor que lhes encheu os olhos de lágrimas: "rise, sally, rise, wipe your weepin eyes / and put your hand in your hips / an let your backbone slip / o, shake it to the east / o, shake it to the west" ( $f c g$ 4), "we gotta dance to keep from cryin" (v15), até que "alla my niggah temper came outta control / . . \& i talked english loud" ( $f c g$ 12). O texto de Shange é um incentivo à auto-estima, à capacitação e à emancipação das mulheres da sua tripla opressão, como se cada uma delas examinasse a sua função naquela transformação e reconhecesse o seu papel como vital dentro dessa transformação.

Tal como o jazz no texto de Morrison, os ritmos dos blues e os movimentos da dança em Shange denotam uma sexualidade pujante que o puritanismo da sociedade americana considera imoral e até pecaminosa. Expressões artísticas das mais originais na cultura americana, a música e a dança da tradição afro-americana acompanham os negros desde a escravatura e testemunham toda a criatividade e espiritualidade que lhes foi negada, mas também uma desinibida sensualidade, que foi o único aspeto que a perceção dominante registou para a traduzir por bestialidade. Tanto o texto de Morrison como o de Shange desconstroem os binarismos inscritos na cultura ocidental e que subjazem aos estereótipos. Wild, em Jazz, permanece esquiva e não domesticável, mas representa o retorno de Beloved, que a própria mãe vitimou para a proteger de um destino pior. Como o próprio nome indica, esta é, afinal, a filha muito amada. Representação de um passado indizível para Sethe,

Dismantle the Master's House." Eds. Elisabeth Hackett and Sally Haslanger. Theorising Feminisms (New York. OUP, 2006), respetivamente 159-173 e 30-40. 
Beloved é o fantasma encarnado, capaz também de "rememorar" fragmentos de um passado coletivo que remonta a África, à "Middle Passage" e à escravatura.

No texto de Shange, também a voz de uma das mulheres ecoa o sentido de pertença a um passado ancestral, em que não há separação ou conflito entre corpo e alma, como existe nas culturas ocidentais. É o próprio movimento sensual do corpo ao som da música que liberta o espírito. O dilema está, sim, em ser mulher e negra ao mesmo tempo e, ainda assim, conseguir sobreviver. ${ }^{19}$ Shange consegue, assim, desconstruir o logocentrismo da cultura ocidental, cuja tradição judaico-cristã separou corpo e alma, mas juntou interseccionalmente as várias opressões:

... the music waz like smack \& you knew abt that \& still refused my dance waz not enuf / \& it waz all i had but bein alive $\&$ bein a woman \& bein colored is a metaphysical dilemma / i haven't conquered yet / do you see the point my spirit is too ancient to understand the separation of soul \& gender / my love is too delicate to have thrown back on my face. ( $f c g$ 48)

Em qualquer destes mundos imaginários, a música, a dança e uma sexualidade assumida são emancipatórias. Em qualquer das escritas, o vernáculo, o calão e as sonoridades da oralidade de um Black English impõem-se à gramática padrão do Inglês e à gramática social dos códices morais da classe média branca, trazendo ao de cima o "africanismo" de identidades silenciadas. Em Morrison, essa marca (ou "trace") da africanidade é "wild"; em Shange, é "loud";

${ }^{19}$ A ironia com que se expressa este dilema no texto de Shangue não pode deixar de nos recordar o verso de Countee Cullen "to make a poet black and bid him sing!", no seu poema "Yet Do I Marvel" (Color [1925]. New York, NY: Harper \& Brothers, 1953). 
em ambas é presença perturbadora, ofensiva e dissonante, numa ordem racista, classista e sexista naturalizada.

Tal como o texto de Morrison, ao privilegiar um público negro, o texto de Shange é exclusivo porque dedicado às jovens mulheres negras que um dia pensaram no suicídio como fuga para as suas vidas sofridas: "for colored girls who have considered suicide". Como também exclusiva é a experiência a que se alude ao longo do poema, a de crescer como uma mulher negra, sujeita à tripla exploração da sua raça, da sua classe e do seu sexo. Mas, para estas escritoras, tornar os seus textos exclusivos (como seus próprios) é por certo um gesto de revolta contra uma sociedade exclusiva (como excludente), como é a sociedade americana.

O contacto com a escrita destas mulheres ajudou-me a interrogar o sentido que penso entender na teoria da "interrupção poética" tão eloquentemente enunciada por Maria Irene Ramalho Santos. Quando nela leio que "o poético precisa da interrupção do político para se fundar e assim devolver, "intacto", o poder da linguagem" (2000: 2), pergunto-me se o político que irrompe inexoravelmente na escrita destas mulheres não a faz devolver-nos o poder de uma linguagem que nos transforma. E se não estamos também perante um tipo de escrita insurreta, "a denouncer, or interrupter, of the dominant culture of the nation" (Ramalho Santos 2003: 243).

\section{Obras citadas}

Ashcroft, Bill, Gareth Griffiths e Helen Tiffin. The Empire Writes Back: Theory and Practice in Post-Colonial Literatures. London and New York: Routledge, 2003. Print.

Bhabha, Homi. The Location of Culture. London and New York: Routledge, 1994. Print.

Baker, Houston. Blues, Ideology, and African-American Literature: A Vernacular Theory. Chicago: University of Chicago P., 1987. Print. 
Caldeira, Isabel. "Morrison and Pepetela: Confluences of the African Diaspora". Eds. Irene Ramalho Santos and António Sousa Ribeiro. Translocal Modernisms: International Perspectives, Peter Lang, 2008, 91-117. Print.

"Toni Morrison and Edwidge Danticat: Writers-as-Citizens of the African Diaspora, or The Margin as a Space of Radical Openness." Ed. Wilfried Raussert. Companion to InterAmerican Studies. London and New York: Routledge, 2017.

Carabi, Angels. "Nobel Laureate Toni Morrison Speaks about Her Novel Jazz." [1993]. Ed. Denard. Toni Morrison: Conversations: 91-97. Print.

Denard, Carolyn C., ed. Toni Morrison: Conversations. Jackson: U.P. of Mississippi, 2008. Print.

- ed. and with an Introduction. Toni Morrison: What Moves at the Margin. Jackson: U.P. of Mississippi, 2008. Print.

Derrida, Jacques. The Derrida Reader: Writing Performances. Ed. Julian Wolfreys. Lincoln: The University of Nebraska P., 1998. Print.

Ellison, Ralph. "Twentieth-Century Fiction and the Black Mask of Humanity." [1953] Shadow and Act. New York: Vintage Books, 1972. 24-44. Print.

Gates, Henry Louis, Jr. The Signifying Monkey: A Theory of African-American Literary Criticism. Oxford U.P., 1988. Print.

Hoby, Hermione. "Toni Morrison: 'I'm Writing for Black People ... I don't Have to Apologise". The Guardian. Saturday 25 April 201510.30 BST. Web. Acedido a 27.04.2015.

hooks, bell. Yearnings: Race, Gender and Cultural Politics. Boston: South End Press, 1990. Print.

Hull, Gloria T., Patricia Bell-Scott e Barbara Smith, eds. All the Women Are White, All the Blacks Are Men, But Some of Us Are Brave: Black Women's Studies. The Feminist Press at CUNY, 1982. Print.

Langer, Adam. "Star Power". Ed. Denard. Toni Morrison: Conversations, 206-2013. Rept. from "Love Is Toni Morrison's Best Novel in More Than a Decade. Now She's Aiming Even Higher." Book (November/December 2003). Print.

Lorde, Audre. Sister Outsider. New York: Crossing P., 2007. Print.

—_. "Foreword." Eds. Joanne M. Braxton and Andrée Nicola McLaughlin. Wild Women in the Whirlwind: Afra-American Culture and the Contemporary Literary Renaissance. New Brunswick, NJ: Rutgers U. P., 1989, xi-xiii. Print.

Mbalia, Doreatha D. Toni Morrison's Developing Class Consciousness. Selinsgrove, Penn.: Susquehanna University P., 2004. Print.

Morrison, Toni. "Home". Ed. Wahneema Lubiano. The House that Race Built. New York: Vintage, 1998, 3-12. Print.

- Lecture and Speech of Acceptance, Upon the Award of the Nobel Prize for Literature, Delivered in Stockholm on the Seventh of December, Nineteen Hundred and Ninety-three. New York, NY: Knopf, 1994. Print.

- Playing in the Dark: Whiteness and the Literary Imagination. Cambridge: Harvard U.P., 1992a. Print.

—. Jazz. New York, NY: Alfred A. Knopf, 1992b. Print. 
- Beloved. London: Chatto \& Windus, 1987. Print.

—_. "Rediscovering Black History" [1974]. Ed. Denard. What Moves at the Margin, 39-55. Print.

Quijano, Anibal. "Coloniality of Power, Eurocentrism, and Latin America." Neplanta: Views from South 1.3 (2000), 533-580. Web. Acedido a 20.10.2003.

Quijano, Anibal and Immanuel Wallerstein. "Americanity as a Concept, or the Americas in the Modern World-System." International Journal of Social Sciences 134 (November 1992): 549-557. Web. Acedido a 16.01.2000.

Rich, Adrienne. "When We Dead Awaken: Writing as Re-Vision." College English 34.1, Women, Writing and Teaching (Oct. 1972): 18-30. National Council of Teachers of English Stable. Web. Acedido a 11.09.2008.

—. "The Burning of Paper Instead of Children." The Will to Change: Poems 1968-1970. New York, NY: W. W. Norton, 1971, 15-18. Print.

Ramalho Santos, Irene. "Difference and Hierarchy Revisited by Feminism". Revista Anglo-Saxónica. Centro de Estudos Anglísticos da Universidade de Lisboa. Ser. III.6 (2013): 21-46. Print.

- Atlantic Poets: Fernando Pessoa's Turn in Anglo-American Modernism. Hannover and London: University P. of New England, 2003. Print.

_. "Interrupção poética: Um conceito pessoano para a lírica moderna". Veredas 3 (2000): 2-9. Web. Acedido a 12.12.2014.

Shange, Ntozake. for colored girls who have considered suicide/when the rainbow is enuf: a choreopoem. New York, NY: Bantam, 1975. Print.

Spivak, Gayatri Chakravorty. "Can the Subaltern Speak?" Eds. Cary Nelson and Lawrence Grossberg. Marxism and the Interpretation of Culture. Urbana: $\mathrm{U}$ of Illinois P., 1988. 271-313. Print.

Tate, Claudia, ed. "Toni Cade Bambara." Black Women Writers at Work. Introd. Tillie Olsen. New York: The Continuum Publishing Company, 1983, 18-32. Print.

Williams, Sherley Anne. "The Lion's History: The Ghetto Writes B[1]ack." Soundings 76 (Summer-Fall 1993), 245-59. Print. 